\title{
Good Neighbours in Bad Neighbourhoods: Narratives of Dissociation and Practices of Neighbouring in a 'Problem' Place
}

\section{Gwen van Eijk}

[Paper first received, November 2010; in final form, July 2011]

\begin{abstract}
This paper challenges the idea that living in a 'problem' neighbourhood strains neighbour relations, by examining the relation between narratives of dissociation and practices of neighbouring. Several studies have suggested that confrontations with ethnoracial diversity, disorder and stigma would cause residents to withdraw from interacting with their fellow-residents. Based on a mixed-method study in a 'problem' and a 'problem-free' neighbourhood, the paper shows that, while narratives of dissociation may suggest withdrawal, such talk does not necessarily reflect in practices of neighbouring. First, negative neighbourhood talk can go together with efforts to connect with fellow-residents. Secondly, perceptions of diversity or disorder do not matter much when neighbour relations evolve around chance encounters and norms of good neighbouring. Inferring practices from narratives risks reproducing images of deprived neighbourhoods as dysfunctional and applying a double standard in explaining distant neighbour relations, while misrecognising the ways in which residents do maintain neighbourly relations.
\end{abstract}

\section{Introduction}

A recurrent idea in debates on 'problem' neighbourhoods is that people living in such neighbourhoods fail to establish and engage in relationships with their fellowresidents. Living in such places would hinder the formation of personal relationships, because ethnoracial diversity of the population would result in feelings of discomfort or conflicts; because heightened levels of disorder and crime would lead to mistrust; and/or because attempts to avoid the stigma attached to living in such places would translate into strategies of distancing. In such analyses, being confronted with disorder, stigma and diversity would have an effect not only on relationships

Gwen van Eijk is in the Institute for Criminal Law and Criminology, Leiden Law School, Leiden University, P.O. Box 9520, 2300 RA, Leiden, The Netherlands. E-mail: g.van.eijk@law.leidenuniv.nl 
with 'others', but on relationships with fellow-residents in general. This idea of 'problem' neighbourhoods as socially dysfunctional is echoed in socio-political debates on 'fragmented communities' and 'multicultural nightmares' and calls for more 'social cohesion', particularly across ethnoracial boundaries, in neighbourhoods (for example, in the Netherlands and the UK: Blokland, 2003b; Forrest and Kearns, 2001; Amin, 2002; Fortier, 2007).

This paper examines this collection of ideas and makes an effort to empirically substantiate and to theoretically refine them. The paper makes two points. First, it contends that analyses of social processes in 'problem' places need to distinguish carefully between narratives and practices. While narratives of residents living in such places may well suggest conflict, dissociation and withdrawal, this does not necessarily and always mean that practices of neighbouring are affected-at least not for all residents. Several studies have shown a contradictory and complex interplay between narratives and practices, demonstrating how positive and strained relations may exist side by side (for example, Blokland, 2003a; Watt, 2006; Fortier, 2007; Clayton, 2009; Lobo, 2010). Using data from surveys and in-depth interviews, this paper aims to work out this insight in more detail. The second point of the paper is that, in understanding why residents of 'problem' places demonstrate little engagement with their neighbours, political and academic analyses tend to overlook the nature of typical neighbour relations. For many, neighbouring means balancing proximity and privacy and an important norm of good neighbouring is that people keep their distance and respect each other's privacy (for example, Abrams and Bulmer, 1986; Crow et al., 2002; Stokoe and Wallwork, 2003). In understanding why residents of particular places abstain from close, frequent or productive relationships (in terms of getting things done together for the benefit of the neighbourhood), we thus need to take into account the particularities of relations in the context of 'being neighbours'.

The issue is important because a focus on narratives of dissociation risks overlooking that people in 'bad' neighbourhoods actually often maintain 'good' neighbourly relationships (see Forrest and Kearns, 2001). In other words, focusing on these narratives may wrongfully depict a dystopian view of particular neighbourhoods where conflict, disorder and differences are all-pervasive. It suggests that local relationships are dysfunctional where there may in fact be just 'normal' neighbourly relations based on distance and privacy. Furthermore, there seems to be a double standard as to understanding why people abstain from neighbour relations. Social networks have in general become more geographically dispersed as meeting contexts such as work, church, leisure and political organisations are often located outside the neighbourhood (Wellman, 1979; Fischer, 1982; van Eijk, 2010). As the overlap between such settings and neighbourhood has disappeared, the importance of the neighbourhood as context wherein people meet and mate has diminished and for many disappeared (Blokland, 2003b). These developments have commonly been recognised in understanding urban life in contemporary Western cities, but have been neglected in the analysis of neighbour relations in deprived neighbourhoods. Thus, in understanding why people in particular neighbourhoods maintain few or no neighbour relations, politicians and academics tend to apply a double standard: in relation to affluent neighbourhoods, we point at what people do outside their neighbourhood; in the case of deprived neighbourhoods, we seek for an explanation in neighbourhood characteristics. Such a double standard in evaluating behaviour, judging it more 
favourable when it involves the affluent than when it involves the poor, demonstrates a lack of recognition, which is in turn closely linked to a socioeconomically weak position (Sayer, 2005, p. 205). Applying a double standard is not only inaccurate, but it also serves to problematise and stigmatise areas and groups of people and increase the burden of responsibilities as residents of deprived areas have to work much harder to attain a sense of normality or reduction in local social problems (Atkinson, 2006).

The next section sets forth how 'problem' neighbourhoods would undermine local relationships and discusses several points of critique which offer an alternative reading of neighbour relations in such places. Then, after discussing the data, the fourth section compares perceptions of difference and disorder and neighbour relations in a problem and a problem-free neighbourhood. The fifth section discusses the discrepancy between narratives and practices in more detail. The final section offers conclusions and discussion.

\section{Connecting Neighbourhood Problems and Problematic Neighbour Relations}

In a nutshell, the common features, often mentioned in tandem in academic and political analyses, of Western 'problem' neighbourhoods are: a deprived population, often coping with individual problems (for example, drug/alcohol abuse, mental disorders); a disproportionate share of ethnoracial minority categories as well as ethnoracial diversity; high levels of crime and disorder and fear of crime; and a pervasive stigma, attached to its 'problem population' as well as the place itself. The alleged negative effect of poverty concentration can be traced back to the Chicago School's concept of 'social disorganisation' (see for example, Shaw and
McKay, 1969; Sampson and Groves, 1989). While there is some evidence of the correlation between neighbourhood poverty and absent local ties, the mechanisms through which poverty concentration in itself would undermine relationships are not clearly developed (Warner and Rountree, 1997, p. 521). Deprivation seems to matter mainly because of the "undesirable correlates of poverty" (Massey, 1996, p. 395): joblessness, crime, family dissolution, drug abuse, alcoholism, disease and violence. High-poverty neighbourhoods often have a higher share of social housing and thus these neighbourhoods accommodate more residents with social and psychological problems who cannot access the private housing market. Even when residents do not have problems themselves, they are thus likely to encounter problems and experience more disorder. In addition, the concentration of poverty goes together with higher levels of crime. Perceived disorder and fear of crime in turn would promote fewer ties with neighbours and 'mistrust' (Ross et al., 2002; Palmer et al., 2005; Warr, 2005; Guest et al., 2006).

Mistrust affects not only interactions with people who are thought to be antisocial or criminal. There seems to be a process of "ecological contamination" (Sampson, 2009, p. 313; also Hunter, 1974): “all persons encountered in 'bad neighbourhoods' are viewed as possessing the moral liability of the neighbourhood itself". The mechanism that links deprivation, disorder and dissociation thus has to do also with the negative reputation of neighbourhoods, which results from the low status of these places and the perception of both outsiders and residents themselves that these places are 'dumping grounds' for poor people (Wacquant, 2008). Studies have shown that place reputations are associated with the socioeconomic and ethnoracial composition of neighbourhoods (Permentier et al., 2008; 
Sampson, 2009). Often, the presence of 'problem populations' is associated with neighbourhood problems and decay (Wilson and Taub, 2007; Mooney, 2008). According to Wacquant (2008, p. 173), place stigma affects "all realms of existence", including involvements with others, both fellow-residents and people living outside the area. Territorial stigmatisation of Chicago's deprived neighbourhoods and the Paris banlieues

stimulate[s] practices of internal social differentiation and distancing that work to decrease interpersonal trust and undercut local solidarity (Wacquant, 2008, p. 183).

Residents devalue their neighbourhood in order to stress their own moral worth through strategies such as mutual avoidance and scapegoating, and dissociate from their neighbourhood and its residents by stressing that they do not belong there. As residents distance themselves from the neighbourhood and its population, in an attempt to avoid stigmatisation, opportunities for relations with fellow-residents are strained (Palmer et al., 2005; Warr, 2005; Noordhoff, 2008, ch. 5).

Finally, what has received much attention more recently is the alleged negative effect on relationships of ethnoracial diversity in neighbourhoods. Many studies have focused on (contentious) interethnic relations, but it has also been argued that ethnoracial diversity strains relationships in general-regardless of whether they are interethnic or within one's 'own' ethnic category. Using a US-wide survey on various forms of social and political engagement, Putnam (2007) found that people who live in ethnically diverse areas reported fewer neighbours, fewer friends and fewer confidants. People living in multi-ethnic neighbourhoods did not only report fewer interethnic ties but also fewer intra-ethnic ties. Putnam concludes that ethnic diversity strains all forms of social (and political) involvement, which would result from the fact that "many Americans today are uncomfortable with diversity" (Putnam, 2007, p. 158). This feeling of discomfort would be, next to poverty, crime and other notorious factors, a cause of withdrawal from social involvement. Part of the 'effect' of diversity may be mediated through the confrontation with an ethnic-other neighbour, which is more likely if one lives in a multi-ethnic neighbourhood (Lancee and Dronkers, 2010). However, that only explains the impact on cross-category relationships and not on all relationships (which association remains in Lancee and Dronkers's study). Gesthuizen et al. reformulate Putnam's argument as follows

\begin{abstract}
The more diverse a social context actually is in terms of different (ethnic) groups, the less people of one's 'own kind' there are around with whom people feel familiar and with whom people can socially identify, the less people feel comfortable with others and the more they distrust others and the less they will socially connect to other people, even to people of their 'own kind' (Gesthuizen et al., 2009, p. 123).
\end{abstract}

However, there is no reason to assume that mere difference always results in disidentification and withdrawal. We should read these kinds of arguments in relation to socio-political debates in the UK, the Netherlands and other Western countries which paint a picture of a "multicultural nightmare, in which disproportionate diversity undermines social solidarity" (Fortier, 2007, p.113). Concerns about ethnic mixing and the integration, or assimilation, of non-Western minorities, in particular those originally from Islamic countries (Duyvendak et al., 2009), and, more recently, the belief that the 
multicultural society has failed, has led to a preoccupation with interethnic relations and has focused policy attention towards fostering social cohesion. It may thus be a particular kind of diversity that invokes narratives, and perhaps practices, of dissociation.

However, several studies challenge such analyses and suggest that living with difference, stigma and decay is not necessarily and always problematic. For example, in her study on interethnic encounters in an Australian neighbourhood, Lobo finds that such encounters

produce interethnic tensions, indifference and insecurity, but also curiosity, surprise, joy and laughter. Residents overcome the tensions of negotiating and living with difference, through practices of welcoming and even joking about difference (Lobo, 2010, p. 97).

In these interactions, boundaries are temporarily blurred and tension makes place for belonging and understanding.

Nevertheless, it seems more likely that neighbours engage in friendly relations while boundaries, differences and stereotyping remain intact, and this is what makes relations so complicated and disentangling narratives and practices so essential. This is shown in Watt's study in a London borough, in which he observes a tension between "generalized narratives of urban decline" and "more specific descriptions of social interaction in their neighbourhoods which include elements of 'belonging"' (Watt, 2006, p. 786). This tension is summed up by an interviewee who lamented a "lost community" but also had "wonderful neighbours" (Watt, 2006, p. 786). Narratives of urban decline were often linked to the presence of low-status 'others' and 'problem' tenants, demonstrating social distancing. Yet interviewees also demonstrated an inconsistency in describing 'others' and neighbourhood problems in general on the one hand and specific neighbours and personal relations on the other. Such inconsistency, demonstrates, first, the complexity of encounters and relations, and, secondly, the danger of relying too much on narratives for understanding actual personal interactions. Clayton similarly points to the contradictory and complex interplay between differences and encounters: the "forced propinquity of public spaces" offers opportunities for intercultural engagement revolving around mutual interests, such as playing football, but during the football match that he describes, "racial distinctions remain largely intact" (Clayton, 2009, p. 489). Clayton concludes that

racisms and intercultural accommodations exist side by side, making a straightforward distinction between those places which 'work' in terms of positive interethnic relations and those which do not, a misleading binary (Clayton, 2009, p. 494).

Another example is offered in Fortier's analysis of the British documentary The Last White Kids. Fortier notes that the featured family, the Gallaghers, who are "the only white family" remaining in a street in an area in Bradford, live in a "relationship of genial indifference" (Fortier, 2007, p. 110). The documentary shows Mrs Gallagher as she "mechanically lists her neighbours by ethnic background" but also shows her holding a neighbour's newborn baby, "doting over her, trying in vain to pronounce her name" (Fortier, 2007, p. 110). Boundaries remain firmly in place and feature in narratives about the neighbourhood, but this talk does not imply that all interactions and relations are hostile or contentious. Living with difference is multifaceted in nature, Fortier concludes, and she goes on to suggest that living side-by-side, instead of face-to-face, could be read as an 
"ethical relation of indifference" that resembles Simmel's blasé attitude: "an inherent factor of living among strangers in the metropolis" (Fortier, 2007, p. 110).

However, such indifference should not be attributed solely to living among people who are different in terms of their lifestyles, practices, appearances or backgrounds. Indifference is also characteristic of neighbour relations. Studies have shown that good neighbouring

lies in maintaining the tension between cooperation and privacy, helpfulness and non-interference, between friendliness and distance (Allan, 1983; quoted in Buonfino and Hilder, 2006, p. 13; see also Abrams and Bulmer, 1986; Crow et al., 2002).

Distancing manifests itself in the boundedness of interactions and transactions. That is, spatially, neighbour relations are often restricted to spaces close to the home, but usually outside the home rather than inside (Stokoe and Wallwork, 2003), and are heavily dependent on chance encounters. In addition, exchanges are often restricted to the kind of help that does not require too much personal involvement: taking care of plants, mail and pets during holidays, exchanging keys, borrowing food items or tools, offering support in case of emergencies and usually not offering emotional support (Abrams and Bulmer, 1986; Wellman and Wortley, 1990; Crow et al., 2002; Völker and Flap, 2007; Kusenbach, 2008). Norms for good neighbouring put up boundaries and thus may reproduce boundaries based on differences rather than dissolve them (van Eijk, 2011). However, while the boundedness of many neighbour interactions works to maintain distinctions, it also makes possible interaction despite differences and difficulties. That is, because many neighbours are neither seeking nor expecting intimacy, closeness or friendship, differences cease to matter much in the actual encounters that occur between neighbours. For understanding relations between neighbours we thus also need to take into account the specificities of neighbouring, as they may offer an alternative reading of limited neighbour interactions in all sorts of neighbourhoods, whether made up of affluent or poor residents.

\section{Data and Methods}

The paper is based on a mixed-methods study among people living in two neighbourhoods in Rotterdam: a multi-ethnic deprived 'problem' neighbourhood (Hillesluis) and a mono-ethnic (i.e. White and Western) affluent 'problem-free' neighbourhood (Blijdorp). In order to understand whether living in a 'problem' neighbourhood matters for neighbour relations, we need to be able to compare and thus a structured questionnaire was used to map personal networks. Unstructured indepth interviews were used to gain insight into the link between narratives of dissociation and neighbouring practices (see for a detailed description of the study, data and methods, see van Eijk, 2010).

Two surveys on social networks and support were carried out in 2007 through faceto-face interviewing $(n=195)$. In Hillesluis, residents were included randomly; in Blijdorp the sample was stratified for streets. We used 18 name-generating questions (McCallister and Fischer, 1978; Völker and Flap, 2007), to map not entire personal networks but rather those network members that had offered help with finding a job or house, getting politically involved or doing voluntary work, personal troubles, and odd jobs and providing tools or groceries to borrow. In addition, we asked whether respondents had a neighbour they 'particularly trust'. Neighbour relations thus could 
be reported as network members in two ways: through this specific name-generating question about neighbours and through the general name-generating questions. In this way, for each respondent we assembled a list of network members. For each of the network members, we asked further questions to gather information on the type of relationship (family member, friend, neighbour, etc.), place of residence (neighbourhood, city, etc.), shared activities and expected future support. Here, I look only at those network members who were described by respondents as 'neighbours' $(n=243)$.

In 2009, I approached several survey respondents for a follow-up in-depth interview. I interviewed 15 Hillesluisians and 15 Blijdorpers (12 men and 18 women; 11 in their 30s, 4 in their 40s, 9 in their 50s and 6 aged 60 and older; 18 are of native Dutch origin, 12 of non-Dutch origin; 13 have limited or low education and 17 have high education). In this article, I draw mainly on the conversations about neighbourhood and neighbours: whether people thought they 'fit in' with the neighbourhood population, how they interacted with their neighbours (those mentioned as network members as well as not-mentioned next-door neighbours) and how they thought about difference and sameness in relation to their neighbours. The respondents introduced in sections 6 and 7 illustrate several themes that appeared in analysing the in-depth interview data.

\section{Perceptions of Disorder and Difference in the Two Neighbourhoods}

Hillesluis is a pre-war neighbourhood in the south of Rotterdam, originally built for working-class families who would work in the harbour (see Blokland, 2003b). After the Second World War, Hillesluis attracted many non-Western immigrants: guest workers and their families from Turkey and
Morocco, and later refugees from Africa and the Middle East. Hillesluis is often described as a problem area and was appointed as an urban renewal area. Local and national governments have invested to improve housing standards, local economy, public places, liveability and its reputation, in part by demolishing and replacing part of the social housing stock by more expensive owneroccupier housing.

Blijdorp is a quiet and 'problem-free' prewar neighbourhood just north of the city centre. The area is particularly attractive for young singles, couples and small families, who are rapidly replacing a now elderly population. There are no known problems or renewal projects occurring.

In both areas, many dwellings are apartments although in Blijdorp they are generally more spacious and better maintained. Residential mobility in both areas is comparable. Differences show mainly in the percentage of social housing, the socioeconomic status and ethnic background of the population, residents' experience of crime and disorder, and perceptions of diversity (Table 1).

In 2007, more Hillesluisians than Blijdorpers were unsatisfied with their neighbourhood and often experienced drunk people on the streets, nuisance, littering, vandalism of public property and cars, drugrelated nuisance and violence. In 2009, even fewer Hillesluisians were satisfied with their neighbourhood (51 per cent) and the percentage of people experiencing nuisance and disorder had gone up, while in Blijdorp not much had changed. My own surveys carried out in 2007 show that Hillesluisians were more likely to say they feel (very) unsafe at home or walking around at night than Blijdorpers. Furthermore, the survey asked respondents whether they thought that fellow-residents in general and fellowresidents they personally know have a similar or different 'lifestyle', compared with their 
Table 1. Neighbourhood characteristics: sociodemographics, housing stock, perceptions of disorder and crime, safety and diversity in the two research neighbourhoods (percentages)

\begin{tabular}{|c|c|c|c|}
\hline & Hillesluis & Blijdorp & Rotterdam \\
\hline Population (in research area, 2007) & 6197 & 5049 & 587161 \\
\hline \multicolumn{4}{|l|}{ Sociodemographics and housing stock } \\
\hline Income below poverty line (2006) & 28 & 7 & 16 \\
\hline High income $(2006)$ & 4 & 27 & 15 \\
\hline Income out of wage or profit (2006) & 56 & 76 & 58 \\
\hline Unemployment benefits (2006) & 29 & 5 & 16 \\
\hline Native Dutch (2009) & 19 & 75 & 53 \\
\hline Non-Dutch, Western (2009) & 7 & 13 & 10 \\
\hline Non-Western (2009) & 74 & 11 & 36 \\
\hline Age $<20$ years $(2009)$ & 30 & 13 & 23 \\
\hline Social housing (2009) & 53 & 10 & 49 \\
\hline \multicolumn{4}{|l|}{ Perceptions of disorder and crime (2007) } \\
\hline Satisfied with the neighbourhood & 65 & 90 & 80 \\
\hline Nuisance caused by youth groups & 27 & 5 & 14 \\
\hline Drunk people on the streets & 7 & 2 & 5 \\
\hline Litter on the streets & 44 & 24 & 33 \\
\hline Graffiti on walls/buildings & 9 & 12 & 15 \\
\hline Vandalism of phone/bus booths & 26 & 5 & 18 \\
\hline Nuisance cased by drug use/dealing & 17 & 2 & 7 \\
\hline Assault & 6 & 2 & 4 \\
\hline Threat of violence & 8 & 1 & 3 \\
\hline Vandalism/theft from cars & 22 & 9 & 17 \\
\hline \multicolumn{4}{|l|}{ Safety and diversity (2007) } \\
\hline Feeling not safe (at all) at home & 20 & 2 & - \\
\hline Feeling not safe (at all) walking around at night & 55 & 13 & - \\
\hline Fellow-residents are quite different & 63 & 12 & - \\
\hline Fellow-residents I know are quite different & 33 & 11 & - \\
\hline
\end{tabular}

Note: Statistics cover the administrative areas, which are larger than the research area. Income below poverty line is a standardised measure used by the Dutch government to assess eligibility for benefits. High income: compared with 20 per cent highest incomes of the Dutch population (given a 40-40-20 income classification). Non-Western: (one of the parents) born in Turkey or following continents: Africa, Latin America and Asia (excluding Indonesia and Japan). Social housing is owned mainly by housing corporations. Neighbourhood satisfaction and perception of disorder and crime based on municipal survey. Perception of disorder and crime shows percentage of respondents who often experience problems.

Sources: Rotterdam, Centrum voor Onderzoek en Statistiek. Safety and diversity statistics based on author's own surveys (2007).

own lifestyle, and far more Hillesluisians said that their fellow-residents are different from them. The question is whether and how differences in perceptions of safety and diversity affect the formation of relationships with fellow-residents.

\section{Neighbour Relationships in the Two Neighbourhoods}

If living in a 'problem' neighbourhood negatively affects neighbouring because people withdraw from interacting with 
fellow-residents, we would expect Hillesluisians to be less likely to report neighbours as network members. However, comparing the two residential categories (using the 2007 survey data) shows a small and non-significant difference between Hillesluisians and Blijdorpers in reporting at least one neighbour (55 and 66 per cent respectively). Of those who report a neighbour, most Blijdorpers (40 per cent) report two, whereas most Hillesluisians report only one (55 per cent; Kendall tau-c for number of neighbours $=0.231, \mathrm{p}<0.05$ ). However, the average number of neighbours reported differs only slightly (1.85 vs 2.22, non-significant).

How do these (minor) differences hold up in a multivariate analysis? Table 2 shows the results of a logistic regression analysis. The dependent variable is whether the respondent mentioned one or more neighbours as network member(s) versus none. Independent variables cover individual characteristics known to matter for neighbouring (i.e. having young children (aged 0-13), being single and length of residence) and variables that are relevant for investigating the link between living in a problem neighbourhood and perceiving disorder and diversity on the one hand and maintaining neighbour relations on the other (i.e. place of residence, whether one feels safe and whether one assesses that fellow-residents in general have a different lifestyle). Including other individual-level sociodemographic variables such as socioeconomic status did not produce a better statistical model.

First of all, it should be noted that both models explain only a small part of the variation in whether one reported a neighbour or not (indicated by a low Nagelkerke $R^{2}$ statistic). Other variables, not covered in the survey, thus may do a better job in explaining differences in neighbouring. Further, the multivariate analysis shows that living in Hillesluis, the 'problem' neighbourhood, and perceptions of diversity and safety are not significantly associated with whether one reported at least one neighbour as a network member or not. Having young children (aged 0-13) is in general positively associated with neighbouring (model 1), but measuring the interaction between neighbourhood and having young children shows that parents living in Hillesluis are less likely to report a neighbour (model 2). Forty-four per cent of the Hillesluis parents reported a neighbour as a network member,

Table 2. Results of logistic regression analysis on reporting at least one neighbour as network member $(N=180)$

\begin{tabular}{lrrrrr}
\hline & \multicolumn{2}{c}{ Model 1 } & & \multicolumn{2}{c}{ Model 2 } \\
\cline { 2 - 3 } \cline { 5 - 6 } & \multicolumn{1}{c}{$B$} & Wald & & $B$ & Wald \\
\hline Lives in Hillesluis & -0.463 & 1297 & & -0.626 & $* 5466$ \\
Has young children & 1042 & $* 6320$ & & 0.617 & $* 6417$ \\
Is single & 0.473 & 1910 & & 0.473 & 1898 \\
Feels safe at night & 0.419 & 1135 & & 0.424 & 1159 \\
Lifestyle of fellow-residents is different & 0.612 & 2299 & & 0.672 & 2769 \\
Years in dwelling & 0.030 & 2888 & & 0.029 & 2803 \\
Interaction: children * Hillesluis & & & & -0.611 & $* * 6733$ \\
Constant & -0.493 & 0.977 & & -0.117 & 0.065 \\
-2 LL & 223.492 & & & 215.391 & \\
Nagelkerke $R^{2}$ & 0.096 & & & 0.152 & \\
\hline
\end{tabular}

Note: significance level: $* \mathrm{p}<0.05 * * \mathrm{p}<0.01$. 
compared with 89 per cent of the Blijdorp parents (Cramer's $\mathrm{V}=0.471, \mathrm{p}<0.01$ ). Comparing respondents without young children shows no difference (58 vs 59 per cent). Nevertheless, the difference in the number of neighbours reported is small and non-significant (1.92 vs 2.17). Because of the small number of parents in the study ( $n$ $=54$ ), we should be cautious about interpreting statistical differences. Yet it may suggest that living in a 'problem' neighbourhood does not affect all residents alike. Studies suggest that neighbouring for parents is differently shaped than neighbouring for non-parents. Parents tend to do more neighbouring due to the locus of their children's life-world (making friends and playing), the convenience of local support and, sometimes, the overlap of school and neighbourhood (for example, Dawkins, 2006; Weller and Bruegel, 2009). However, parents may also be more 'picky' about neighbours because their children's safety and socialisation are at stake and thus limit interaction with neighbours whom they think have deviant lifestyles (for example, Ceballo and McLoyd, 2002; Pinkster and Droogleever Fortuijn, 2009). It might thus be parents' particular position that is related to withdrawal.

However, for other residents, living in a problem or problem-free neighbourhood does not predict neighbouring, nor does it seem to affect the 'quality' of neighbour relationships. (See Table 3; data show characteristics of individual relationships with network members reported as 'neighbours'.) Neighbours were reported in response to different name-generating questions, but both Hillesluisians and Blijdorpers reported most as 'trusted neighbours' (question: Is there a neighbour you particularly trust?). Further, neighbours were mentioned in relation to borrowing tools and food and much less to other help situations, which demonstrates the boundedness of neighbouring in both neighbourhoods. Both groups do not 'feel particularly close' to their neighbours, nor did many of them report joint dinners or outdoor activities in the past three months. Neighbour relations in Blijdorp are thus neither more prevalent nor more intimate. If anything, Hillesluisians' neighbour relations are maintained more frequently and for longer. Finally, in terms of expected future support, Hillesluisians define their neighbour relations more broadly as they would call on them in a greater number of occasions (3.8 out of 7 , vs 2.5 in Blijdorp). There is thus no evidence that Hillesluisians' neighbour relations are of lesser 'quality'.

A systematic and detailed comparison of practices of neighbouring thus shows many similarities. Furthermore, whether neighbourhood diversity, disorder or stigma matters for one's neighbour relations, seems to depend on what people desire and need from their neighbours. Parents of young children have reasons to want to interact more with their neighbours. However, simultaneously they also have more reasons to be careful about who they neighbour with. Yet many others, abiding by norms of good neighbouring, are probably fine with keeping their neighbours at a distance, which could explain why general perceptions of diversity and safety fail to impact on relations. However, an investigation based solely on Hillesluisians' narratives on neighbours and neighbourhood would probably lead us to a different conclusion, as their narratives, as we will see, indeed suggest dissociation. In the following sections, I want to draw attention to how such narratives can go together with maintaining and even pursuing neighbour relations. 
Table 3. Characteristics of neighbour relations

\begin{tabular}{|c|c|c|c|}
\hline & Hillesluis $(n=98)^{a}$ & Blijdorp $(n=145)^{a}$ & Significance \\
\hline \multicolumn{4}{|l|}{ Name-generating question } \\
\hline Trust neighbour & 85 & 87 & ns \\
\hline Social/political activities together & 7 & 2 & ns \\
\hline Small tasks in/around the house & 9 & 4 & ns \\
\hline Ask for small help when sick & 5 & 10 & ns \\
\hline Borrow groceries/tools & 17 & 15 & ns \\
\hline Talk politics & 9 & 4 & ns \\
\hline Talk personal/consider opinion & 8 & 3 & ns \\
\hline Otherwise important & 2 & 2 & ns \\
\hline Find job/house & 1 & 0 & ns \\
\hline Mean number of name generators & 1.29 & 1.18 & ns \\
\hline \multicolumn{4}{|l|}{ Expected future help } \\
\hline Finding a job & 82 & 95 & Cramer's V $=.200 * *$ \\
\hline Finding a house & 90 & 91 & ns \\
\hline Small tasks in/around the house & 95 & 98 & ns \\
\hline Small help when sick & 95 & 97 & ns \\
\hline Borrow groceries/tools & 94 & 92 & ns \\
\hline Talk personal & 96 & 100 & Cramer's V $=.159^{*}$ \\
\hline Consider opinion & 95 & 97 & ns \\
\hline Mean number of future support & 3.81 & 2.52 & $\mathrm{~T}=4.501 * * *$ \\
\hline $\begin{array}{l}\text { Feel especially close to } \\
\text { In previous three months }\end{array}$ & 16 & 9 & ns \\
\hline Visited each other & 52 & 61 & ns \\
\hline Had dinner together & 26 & 13 & ns \\
\hline Did outdoor activities together & 9 & 12 & ns \\
\hline Years known & 10.0 & 7.4 & $\mathrm{~T}=2.953 * *$ \\
\hline Frequency contact & & & Kendall tau-c $=.389 * * *$ \\
\hline Every day & 38 & 6 & \\
\hline Few times a week & 32 & 35 & \\
\hline Once a week & 19 & 35 & \\
\hline Less often & 11 & 24 & \\
\hline
\end{tabular}

${ }^{\mathrm{a}}$ Number of network members.

Note: significance levels: ${ }^{*} \mathrm{p}<0.05 * * \mathrm{p}<0.01 * * * \mathrm{p}<0.001$.

\section{Narratives of Dissociation and Connectedness}

Of course, there are residents who through talk dissociated from the neighbourhood and its population and indeed did not interact much with neighbours. Jeffrey (33, single, 1 child, 11-20 years in Hillesluis), for example, felt that living in Hillesluis was not conducive to developing 'sociable' relationships with fellow-residents. Jeffrey contrasted Hillesluis with Vreewijk, where he grew up: "two different worlds". Vreewijk is known as a peaceful 'village' in the city that has partly maintained its character of a 'working-class community'. For Jeffrey, Hillesluis did not fit in with his imagined future and his aspirations and he would rather move to Vreewijk

GE: What's so different there, compared with [Hillesluis]? 
Jeffrey: Well, you know, when I grew up there, for example, you could count the non-Western minorities [allochtonen] on your hand, on your fingers, and you still can, that I think has something to do with it.

GE: How does that make it a different neighbourhood?

Jeffrey: Well, that makes it more suitable, I think that the middle-class people live there, and well, people who work, let's put it that way, you know, social interaction, normal things, you know, and you just don't have that here in the street.

Jeffrey also pointed to the type of housing: because in his part of Hillesluis there were mainly apartments, people "don't talk to each other and [say] hello and wave and that's it", while in Vreewijk the singlefamily dwellings made interactions easier. His image of Hillesluisians as not "sociable" and "social", as he put it, was confirmed when his new next-door neighbours had not introduced themselves to him. Their children, however, did play together. And although Jeffrey indeed did not report any neighbours as network members, he did maintain "normal contact" with his other next-door neighbours, "helping each other out a bit" watching each other's stuff, and he would even consider leaving his son with them in case he had to go somewhere unexpectedly.

Then there are residents who, like Jeffrey, were not too happy about the changed neighbourhood population. It has been argued that particularly the 'original' residents-native Dutch, long-term residents who have seen the area transform into a multicultural neighbourhood (Reijndorp, 2004)_are uncomfortable with increasing diversity and the changes that this has brought. Particularly their narratives suggest withdrawal. However, an investigation into their practices of neighbouring shows that withdrawal and seeking connectedness can go together. Here are two examples of residents who were not satisfied, but who did just the opposite of withdrawing.

Kristel (32, married, 2 children, 11-20 years in Hillesluis) felt that she fitted in with the people in the neighbourhood, but she wanted to move

\begin{abstract}
What is unfortunate, and not that I have something personally against foreigners, but very few Dutch families live here. That's something I deeply regret. And that's a reason to move ... Not because of the neighbourhood, because I don't have any problems with the neighbourhood and the people who live there, but I think it would be nice that when I sit outside that I hear people speaking Dutch and not just Turkish or Moroccan.
\end{abstract}

She did not think she had anything in common with the 'foreign' families. For example, a group of mothers would go to the park in the summer and sit there for three hours, and for Kristel that was a problem because she had dinner at six o'clock. The women did ask her to sit with them, but Kristel thought she would feel uncomfortable when they would all talk Moroccan. In the 14 years that she lived in Hillesluis, she had not seen it change.

While her narrative is one of dissociation, in practice she was active in her street, putting up garlands for the Football World Cup and asking the housing association for plants to put outside. Her (Moroccan and Turkish) neighbours had helped, driving to the hardware store and flower shop. Furthermore, a friendship had developed between her and her neighbour (who she reported as a neighbour whom she particularly trusts), discussing personal matters and spending time together with their children, despite that Kristel thought they were very different 
She is Hungarian and she has very different norms and values than I have. I'm [in favour] with the children of peace and quiet, order and good and healthy eating, eating on time, in bed on time. And with her it was that, in the afternoon they would have a hot meal at one o'clock, and at six o'clock again [a] hot [meal]. And then the little one went to bed at seven o'clock, at other times at nine. For them that's normal because they're used to it in Hungary, but with us it's peace and order.

Another resident who sought connection is Claudia (46, married, 1 child, 21-30 years in Hillesluis). She lamented being the only Dutch person in her street and not interacting more with her neighbours. Having lived there for 28 years, she still feels Hillesluis is "my neighbourhood", but she wanted to move away because the neighbourhood had changed for the worse. First, she does not like all the "foreign shops". Secondly, at the schoolyard of her child's school everyone sorts out into groups and speaks their native language, which makes her "feel like a foreigner in my own country". However, while the neighbourhood "is not what it used to be", Claudia's response is not to withdraw. First of all, she knows the groups on the schoolyard and had even told them that it made her uncomfortable that they all spoke foreign languages (their response was to laugh and give Claudia a hug). Furthermore, she reaches out to establish connections, but gets disappointed when things do not work out and she finds an explanation in their different "cultures". She used to be involved in Opzoomeren (an initiative through which residents can apply for financial support to organise street activities, such as cleaning, a barbeque or a Christmas tree), but two years later she had given up because she is the only Dutch person in her street, she felt she had to do everything by herself, many others work and because of language differences.
However, "That doesn't mean that they are not nice neighbours"

Because two years ago we had a Turkish foster child and that was really appreciated by the [Turkish] neighbours, that we did that, so we got food and yes that was really nice. And that's, in any case if there's something, like last year during football then the neighbours are also watching and then it's like "Tea?". Then you get a cup of tea and that's just really nice, really nice.'

So while Claudia did maintain relationships with their next-door neighbours, she still regretted that she was not able to form more intimate ties with her fellow-residents. She thinks she is very different from her next-door neighbours and, while differences manifest themselves in mundane activities (being away from home, sitting in the garden), Claudia points out their "different cultures".

Nevertheless, wanting to move away and not feeling at home can go together with maintaining relations with neighbours. The two women made an effort to get in touch with people but feel their efforts are a dead end. Ironically, that Claudia's efforts are not returned confirms her feeling that she does not belong in Hillesluis anymore. In addition, her encounters seem to reinforce her idea that she is 'culturally' different from her fellow-residents. Her narratives of dissociation are thus deeply interwoven with her interactions with fellow-residents (see Blokland, 2003a). The interplay between narratives and practices is thus complicated and sometimes contradictory, as perceptions also result from relations and practices (Tilly, 1998, p. 102). This shows that we should be careful not to assume that narratives of dissociation mean actual dissociation. Furthermore, interactions are not only, and perhaps not even in the first place, shaped by perceptions, but also by 
routine-based and chance encounters and norms about how to socialise with each other.

\section{Chance Encounters and 'Good' Neighbouring}

Finally, I want to argue that the boundedness of neighbour relations and norms of good neighbouring can negate experiences of difference or dissatisfaction. Neighbour interactions are often shaped by chance encounters and ideas about 'good neighbouring' rather than by affectivity or attempts to establish friendships. Many respondents did not seek connectedness with their neighbours and maintained neighbourly relations despite interpersonal differences or dissatisfaction with the neighbourhood.

Neighbouring revolves more around affinity than affectivity (Blokland, 2003b, p. 80 ). Ties based on affectivity and affinity are both sociable ties, but the first involves an emotional involvement while the latter involves a rational engagement, based on shared membership of a category, organisation or imagined community. Because of this, affinitive relationships require much less similarity than do affective relationships (Allan, 2008; Pahl and Pevalin, 2005). Neighbour relations are attached in the first place to a shared space (street, block, shared fence or roof) and they are usually nonchosen. People might maintain such relations because they believe in the value of 'good neighbouring' (Blokland, 2003b): offering help when needed and being polite and friendly towards one another. Being 'good neighbours' also means working out a balance between proximity and privacy and this means that 'keeping oneself to oneself' is important, too (Abrams and Bulmer, 1986; Blokland, 2003b; Kusenbach, 2008). Hence the proverb 'good fences make good neighbours'. Neighbouring often involves the 'typical' small exchanges such as greetings and brief chats, borrowing and help in case of emergencies (Wellman and Wortley, 1990; Plickert et al., 2007; Völker and Flap, 2007; van Eijk, 2011). Asking for much more would in many cases breach an understanding of what neighbouring is about-it could easily be experienced as nosiness and intrusion (Abrams and Bulmer, 1986; Crow et al., 2002).

These norms and the non-chosenness of one's neighbours shape neighbouring as bounded relations. This is confirmed by the survey data: few neighbours had offered a wide range of support; many were only 'trusted neighbours'. Furthermore, when we asked respondents what they meant by 'trust', 60 per cent referred to exchanging keys, taking care of plants and mail during holidays and help in case of an emergency. This goes for both Hillesluisians and Blijdorpers.

People's low expectations regarding neighbours explains why whether one perceives fellow-residents as different, or feels that one does not fit in or that the neighbourhood has changed for the worse, does not affect neighbouring. Respondents interacted with their neighbours even when they were not particularly fond of them. For example, Riet (63, married, 31-50 years in Hillesluis) had discovered that two of the neighbours whom she had reported as 'trusted neighbours' had racist sentiments: one was supporting a Dutch right-wing party and the other was complaining about "too many foreign kids" who would cause a nuisance playing in the street. Being married to a Turkish man and self-identifying as a Turkish woman, this discovery had put a strain on Riet's relationship with them. However, when I suggested that she might not report them as trusted neighbours anymore, Riet replied: "No, no, I would say the same".

Maureen (38, widowed, 6 children, 1120 years in Hillesluis) also stressed that her neighbours were very different from her in 
terms of 'culture' (her neighbours married off their children and had limited contact with Dutch people), parenting (her neighbours would not let their children play outside unsupervised so they had to play in the corridors, which caused nuisance) and cuisine (her neighbours could not appreciate the food that Maureen would sometimes bring them, which might have to do with their faith). Yet she and her neighbours exchanged minor and major services such as lifting things, wallpapering their homes, using her computer and the Internet, helping their children do homework and watching them after school.

The negating of difference also characterised several of the neighbour relationships that Blijdorpers maintained. Dominique (39, single, 11-20 years in Blijdorp), for example, had new neighbours whom she thought were very different, being from India they had a "whole different culture". Nevertheless, when they just moved in they came knocking at her door to ask about heating and washing systems and she helped them out. She had lent them a DVD to watch and they had invited her over for dinner, an invitation she had accepted.

Cees (62, married, 1 child at home, 1120 years in Blijdorp) thought he had little in common with his neighbours. He traded in goods and had his office at home and although he was not the only one doing this, others were rather "bookkeeper or accountant, piddling about in maps, all day behind a desk screen". He was not particularly fond of his next-door neighbours, who talked too much and had very different interests, yet in times of need Cees would lend a hand-for example, picking up his neighbour when he had a flat tyre with his bike-and, more generally, would make small talk about "conifers and roses" and what not. Cees' interaction with his neighbours was ultimately based on chance encounters and politeness.
These are some examples of how neighbour interactions were mainly based on chance encounters and values of good neighbouring. While some neighbours did visit each other, it is more prevalent that interactions followed from people running into each other outside their home. This illustrates the boundedness of neighbour relations, which helps to explain why, for at least part of the population, living in a 'problem' neighbourhood does not mean much for whether or not they maintain ties with fellow-residents. Differences, neighbourhood problems and dissatisfaction might be at the foreground in neighbourhood narratives, but they do not necessarily trickle down to the everyday practice of neighbouring.

\section{Conclusion}

This paper has demonstrated the need to be cautious about inferring practices of distancing and withdrawal from narratives of dissociation. Narratives and practices can be contradictory and people living in 'bad' neighbourhoods can still maintain 'good' neighbour relationships. This may be different in places where stigmas of place and poverty are more severe and levels of crime and disorder higher. However, even here neighbour relations may also be shaped by day-to-day encounters, efforts to connect and norms such as respecting each other's privacy.

Grounding an analysis of relations in narratives risks painting a false dystopian picture of already stigmatised neighbourhoods. In doing so, there is a danger that research perpetuates the view that there is something wrong with how people in 'problem places' interact with each other-or that there is something wrong with themand that residents need to take up more responsibilities in order to solve local 
problems. Furthermore, it is not productive to advocate a policy focus on local relations and social cohesion as it fundamentally conflicts with social changes that have impacted on the formation and location of networks and relations (notably the separation of neighbourhood and domains of work, leisure, etc.) and the nature of many neighbour relations (as shaped by the balancing of proximity and privacy). Finally, urban research should avoid applying and reproducing double standards and uncover them in lay and socio-political perspectives. This paper has aimed to uncover the double standard in expectations and obligations towards neighbouring and offered an alternative reading of ambiguous and distant neighbour relations, not as something produced (only) by neighbourhood problems but as a result of the interplay between dealing with differences and seeking connectedness and something inherent to the nature of neighbour relations.

\section{Acknowledgements}

The author would like to thank two anonymous referees for their insightful comments.

\section{Funding Statement}

The research for this article was funded by the OTB Research Institute for the Built Environment, Delft University of Technology. The article was written while the author received a personal grant from the Niels Stensen Foundation.

\section{References}

Abrams, P. and Bulmer, M. (1986) Neighbours. Cambridge: Cambridge University Press.

Allan, G. (2008) Flexibility, friendship, and family, Personal Relationships, 15(1), pp. 1-16.

Amin, A. (2002) Ethnicity and the multicultural city: living with diversity, Environment and Planning A, 34(6), pp. 959-980.
Atkinson, R. (2006) Spaces of discipline and control: the compounded citizenship of social renting, in: J. Flint (Ed.) Housing, Urban Governance and Anti-social Behaviour, pp. 99-116. Bristol: Policy Press.

Blokland, T. (2003a) Ethnic complexity: routes to discriminatory repertoires in an inner-city neighbourhood, Ethnic and Racial Studies, 26(1), pp. 1-24.

Blokland, T. (2003b) Urban Bonds. Cambridge: Polity Press.

Buonfino, A. and Hilder, P. (2006) Neighbouring in Contemporary Britain. York: Joseph Rowntree Foundation.

Ceballo, R. and McLoyd, V. C. (2002) Social support and parenting in poor, dangerous neighborhoods, Child Development, 73(4), pp. 1310-1321.

Clayton, J. (2009) Thinking spatially: towards an everyday understanding of inter-ethnic relations, Social \& Cultural Geography, 10(4), pp. 481-498.

Crow, G., Allan, G. and Summers, M. (2002) Neither busybodies nor nobodies: managing proximity and distance in neighbourly relations, Sociology, 36(1), pp. 127-145.

Dawkins, C. J. (2006) Are social networks the ties that bind families to neighborhoods?, Housing Studies, 21(6), pp. 867-881.

Duyvendak, J. W., Hendriks, F. and Niekerk, M. van (Eds) (2009) City in Sight. Amsterdam: Amsterdam University Press.

Eijk, G. van (2010) Unequal Networks: Spatial Segregation, Relationships and Inequality in the City. Amsterdam: IOS Press.

Eijk, G. van (2011) 'They eat potatoes, I eat rice': symbolic boundary making and space in neighbour relations, Sociological Research Online, 16(4) (http://www.socresonline.org .uk/16/4/2.html).

Fischer, C. S. (1982) To Dwell among Friends. Chicago, IL: University of Chicago Press.

Forrest, R. and Kearns, A. (2001) Social cohesion, social capital and the neighbourhood, Urban Studies, 38(12), pp. 2125-2143.

Fortier, A.-M. (2007) Too close for comfort: loving thy neighbour and the management of multicultural intimacies, Environment and Planning D, 25(1), pp. 104-119.

Gesthuizen, M., Meer, T. van der and Scheepers, P. (2009) Ethnic diversity and social capital in Europe: tests of Putnam's thesis in 
European countries, Scandinavian Political Studies, 32(2), pp. 121-142.

Guest, A., Cover, J. K., Matsueda, R. L. and Kubrin, C. E. (2006) Neighborhood context and neighboring ties, City \& Community, 5(4), pp. 363-385.

Hunter, A. (1974) Symbolic Communities. Chicago, IL: University of Chicago Press.

Kusenbach, M. (2008) A hierarchy of urban communities: observations on the nested character of place, City \& Community, 7(3), pp. 225-249.

Lancee, B. and Dronkers, J. (2010) Ethnic diversity in neighborhoods and individual trust of immigrants and natives: a replication of Putnam (2007) in a West-European country, in: M. Hooghe (Ed.) Social Cohesion, pp. 77103. Brussels: Royal Academy of Belgium.

Lobo, M. (2010) Interethnic understanding and belonging in suburban Melbourne, Urban Policy and Research, 28(1), pp. 85-99.

Massey, D. S. (1996) The age of extremes: concentrated affluence and poverty in the twenty-first century, Demography, 33(4), pp. 395-412.

McCallister, L. and Fischer, C. S. (1978) A procedure for surveying personal networks, Sociological Methods \& Research, 7(2), pp. 131-148.

Mooney, G. (2008) 'Problem' populations, 'problem' places, in: J. Newman and $\mathrm{N}$. Yeates (Eds) Social Justice, pp. 97-128. Maidenhead: Open University Press.

Noordhoff, F. (2008) Persistent Poverty in the Netherlands. Amsterdam: Amsterdam University Press.

Pahl, R. and Pevalin, D. J. (2005) Between family and friends: a longitudinal study of friendship choice, British Journal of Sociology, 56(3), pp. 433-450.

Palmer, C., Ziersch, A., Arthurson, K. and Baum, F. (2005) 'Danger lurks around every corner': fear of crime and its impact on opportunities for social interaction in stigmatised Australian suburbs, Urban Policy and Research, 23(4), pp. 393-411.

Permentier, M., Ham, M. van and Bolt, G. (2008) Same neighbourhood different views? A confrontation of internal and external neighbourhood reputations, Housing Studies, 23(6), pp. 833-855.

Pinkster, F. M. and Droogleever Fortuijn, J. (2009) Watch out for the neighborhood trap!
A case study on parental perceptions of and strategies to counter risks for children in a disadvantaged neighborhood, Children's Geographies, 7(3), pp. 323-337.

Plickert, G., Côté, R. R. and Wellman, B. (2007) It's not who you know, it's how you know them: who exchanges what with whom?, Social Networks, 29(3), pp. 405-429.

Putnam, R. D. (2007) E pluribus unum: diversity and community in the twenty-first century, Scandinavian Political Studies, 30(2), pp. 137-174.

Reijndorp, A. (2004) Stadswijk. Rotterdam: NAi Uitgevers.

Ross, C. E., Mirowsky, J. and Pribesh, S. (2002) Disadvantage, disorder, and urban mistrust, City \& Community, 1(1), pp. 59-82.

Sampson, R. J. (2009) Disparity and diversity in the contemporary city: social (dis)order revisited, British Journal of Sociology, 60(1), pp. $1-31$.

Sampson, R. J. and Groves, W. B. (1989) Community structure and crime: testing socialdisorganization theory, American Journal of Sociology, 94(4), pp. 774-802.

Sayer, A. (2005) The Moral Significance of Class. Cambridge: Cambridge University Press.

Shaw, C. R. and McKay, H. D. (1969) Juvenile Delinquency and Urban Areas. Chicago, IL: University of Chicago Press.

Stokoe, E. H. and Wallwork, J. (2003) Space invaders: the moral-spatial order in neighbour dispute discourse, British Journal of Social Psychology, 42(4), pp. 551-569.

Tilly, C. (1998) Durable Inequality. Berkeley, CA: University of California Press.

Völker, B. and Flap, H. (2007) Sixteen million neighbors: a multilevel study of the role of neighbors in the personal networks of the Dutch, Urban Affairs Review, 43(2), pp. 256-284.

Wacquant, L. (2008) Urban Outcasts. Cambridge: Polity.

Warner, B. D. and Rountree, P. W. (1997) Local social ties in a community and crime model: questioning the systemic nature of informal social control, Social Problems, 44(4), pp. 520-536.

Warr, D. J. (2005) Social networks in a 'discredited' neighbourhood, Journal of Sociology, 41(3), pp. 285-308. 
Watt, P. (2006) Respectability, roughness and 'race': neighbourhood place images and the making of working-class social distinctions in London, International Journal of Urban and Regional Research, 30(4), pp. 776-797.

Weller, S. and Bruegel, I. (2009) Children's 'place' in the development of neighbourhood social capital, Urban Studies, 46(3), pp. 629-643.
Wellman, B. (1979) The community question: the intimate networks of East Yorkers, American Journal of Sociology, 84(5), pp. 1201-1231.

Wellman, B. and Wortley, S. (1990) Different strokes from different folks: community ties and social support, American Journal of Sociology, 96(3), pp. 558-588.

Wilson, W. J. and Taub, R. P. (2007) There Goes the Neighborhood. New York: Vintage Books. 